University of New Haven

University of

New Haven

Digital Commons@ New Haven

Forensic Science Publications

Forensic Science

2018

\title{
Investigating the isolation and amplification of MicroRNAs for Forensic Body Fluid Identification
}

Kelsie R. O'Leary

University of New Haven

Claire L. Glynn

University of New Haven, cglynn@newhaven.edu

Follow this and additional works at: https://digitalcommons.newhaven.edu/forensicsciencefacpubs

Part of the Forensic Science and Technology Commons

\section{Publisher Citation}

O'Leary, K.R., Glynn, C. L. (2018). Investigating the isolation and amplification of microRNAs for forensic body fluid identification. MicroRNA (Shariqah, United Arab Emirates) 7:187-94.

\section{Comments}

This is the authors' submitted manuscript of the article published in microRNA. The published manuscript is available via EurekaSelect at http://dx.doi.org/10.2174/2211536607666180430153821 


\title{
Investigating the isolation and amplification of MicroRNAs for Forensic Body Fluid Identification
}

\author{
Kelsie R. O’Leary \& Claire L. Glynn \\ University of New Haven
}

\begin{abstract}
Background: The discovery of forensic DNA typing evolved molecular biology far beyond what could have been expected in terms of its forensic application, and now there exists other developments in molecular biology which are ready for application to forensic challenges. One such challenge is the identification of the body fluid source of stains recovered from evidence items and crime scenes. Currently there are significant efforts in the research field to develop novel methods for the molecular identification of body fluids, with microRNAs (miRNAs) revealing great potential. MiRNAs have been shown to have high tissue specificity and are less susceptible to degradation as a result of their small size, which infers great advantages to their potential role for identifying forensically relevant body fluids. Objective: This study investigated the isolation and amplification of miRNAs from forensically relevant body fluids. Method: Venous blood, menstrual blood, semen, saliva, and vaginal material samples were extracted using; miRNeasy ${ }^{\circledR}$ mini kit (Qiagen), mirVana ${ }^{\mathrm{TM}}$ miRNA isolation kit (Ambion), and a modified mirVana ${ }^{\mathrm{TM}}$ method, and the quality/quantity of isolated miRNA was determined. miRNAs previously identified to show specificity for particular forensically relevant body fluids were examined. Real Time-Quantitative PCR (RT-qPCR) was performed targeting 5 miRNAs of interest, miR-451, miR-412, miR-891a, miR-205 and miR124a. Results: This study identified the miRNeasy ${ }^{\circledR}$ mini kit as the optimal method of the three methods investigated for the extraction of miRNAs from body fluids and further validates a selection of miRNAs previously suggested as potential biomarkers. Conclusion: This research highlights the potential of miRNAs as novel markers for the identification of forensically relevant body fluids.
\end{abstract}

\section{Keywords}

Forensic Science; microRNA; DNA; extraction; body fluid identification; expression analysis. 


\section{INTRODUCTION}

It is well established that in criminal investigations, body fluids are a very valuable evidence type. They serve as very informative DNA sources, however the actual nature of the fluid provides probative information, in terms of the body fluid source of the DNA [1]. Current tests available for body fluid identification, both presumptive and confirmative, utilize chemical, immunological, and enzymatic methods. These tests are rapid and have quite good sensitivity, however, many are destructive and encounter a wide number of false positives, while some have quite low specificity [2]. Some forensically relevant body fluids, such as menstrual blood and vaginal material, currently do not have any widely accepted or reliable tests for their identification. These are important evidence types, which if identified can yield great value to an investigation and subsequent testimony, particularly in alleged sexual assault cases, by providing valuable information to the sequence of events by identifying the origin of the victim's DNA. Many years ago, it was suggested that RNA could perhaps counteract many of the limitations of the standard tests. Specifically, messengerRNA (mRNA) was thought to be a suitable candidate for the identification of body fluids, as mRNA revealed that each single tissue type is comprised of cells with unique gene expression profiles [3-9]. However, it was subsequently shown that mRNA are very susceptible to degradation, therefore are not suitable for forensically relevant samples as they are frequently exposed to harsh environments [2, 5, 9-13].

In recent years however, there has been an explosion of interest in microRNAs (miRNAs). The basic structure of miRNA is a short stranded non-coding form of RNA approximately 18-22 nucleotides in length. However regardless of their smaller size when compared to mRNA, they contain a wealth of information and are remarkably robust as a result of their size [14]. The first miRNA, lin-4 RNA, was discovered in 1993 by Lee et al. [15]. Prior to this discovery, the large amount of non-coding RNA was just considered to be 'junk genetic material' that held no significant purpose and was only a product of evolution's debris. The lin-4 RNA is now recognized as the founding member of this abundant class of regulatory microRNAs which has changed the common ideas of non-coding RNA and our understanding [16-17]. MiRNAs are classified as gene expression regulators, which are able to attach to the protein coding mRNA strands and inhibit the transcription of new proteins. The miRNAs rise to fame came about as biomedical researchers discovered that miRNAs were tissue specific and could provide a signature of disease, such as cancer forming in that tissue [18-21]. Their involvement, however with forensically relevant body fluids is only a very recent venture. Their reported tissue specificity sparked the idea that miRNAs could be utilized as markers for body fluids in forensic investigations, whereby specific body fluids would have specific miRNA signatures. Furthermore, the ability to co-extract both miRNA and DNA is a welcome advantage to the forensic community as it allows both body fluid identification and person identification simultaneously with little sample required [22-24]. The extensive research carried out on a global level investigating miRNAs in humans have mainly focused on clinical biological samples e.g. various tissues, cerebral spinal fluids, and cultured primary tissues, with minimal research focused on forensically relevant body fluids e.g. venous blood, menstrual blood, semen, saliva, and vaginal fluid. Previous published studies reported promising results identifying differentially expressed miRNAs for forensic body fluid identification [23, 25-32]. A number of the studies however, showed little agreement between them, with only a small number of miRNAs suggested as potential biomarkers for specific fluids overlapping between studies $[23,25-28,30-31,33-36]$. 
The first to explore the forensic application of miRNAs was Hanson et al. in 2009. Hanson revealed certain miRNAs to be differentially expressed across a range of forensically relevant body fluids [26]. At first, scientists aimed to discover miRNAs that are specific to one particular body fluid, however research studies have been unsuccessful in this search thus far. While some miRNAs are particular to two or more body fluids, it has not yet been proven that any one miRNA is particular to any one body fluid. Furthermore, it is not anticipated that one single miRNA would be used to identify one body fluid. Rather, a panel of miRNAs would be used to represent individual body fluids thereby creating a signature of the particular fluid. Although they are few, the previous research studies conducted in this particular field of study has done much of the work in narrowing down the possible miRNA markers used for the identification of forensically relevant body fluids. In 2013 Wang et al., published a table illustrating some of the previous miRNA findings for particular body fluids in their own research and other research group's publications [29]. While these findings do point out potential miRNAs that could be used for the identification of forensically relevant body fluids, it is also important to note that new miRNAs are being discovered constantly. When Wang published this research in 2013, an array was performed that examined 754 human specific miRNAs. Currently the total count of discovered miRNAs that identify with Homo sapiens is $\sim 2000$ (miRBase). This helps demonstrate that though there are presently no miRNAs known to be specific for one body fluid, the possibility is still there. It could just be that the particular miRNA has not yet been discovered. Further to this, there are numerous DNA isolation kits which are commercially available and have been adapted to be used specifically with forensic samples. To date however, there are no miRNA isolation kits available which have been designed for forensic purposes. As a result, the studies reported previously, have utilized a variety of different methods to extract the miRNA content of the samples examined, and therefore an assessment of an assessment of these methods for miRNA extraction from forensically relevant body fluids is warranted.

This first aim of this research was to investigate two commercial miRNA extraction methods for use with forensically relevant body fluids, as it is crucial this is examined with human body fluids such as venous blood, menstrual blood, semen, saliva, and vaginal material. The second aim of this research was to investigate miRNAs previously reported in the literature for their suitability as novel biomarkers for forensically relevant body fluids.

\section{MATERIALS AND METHODS}

\subsection{Sample Collection}

Following Institutional Review Board (IRB) approval at the University of New Haven, the following body fluids were collected from volunteers with written informed consent; venous blood $(n=10)$, menstrual blood $(n=10)$, semen $(n=10)$, saliva $(n=10)$, and vaginal material $(n=10)$. The volunteers consisted of healthy male and female participants, ranging in age from 18-45. Venous blood was collected using venipuncture and standard blood collection procedure into EDTA vials. Semen and saliva were collected into sterile $50 \mathrm{~mL}$ concial tubes. Menstrual blood and vaginal secretions were collected onto sterile cotton tipped swabs. All samples were anonymized upon collection and destroyed after use. All samples were immediately stored at $4{ }^{\circ} \mathrm{C}$ and extracted within 24 hours. 


\section{2 microRNA Extraction}

Three methods of microRNA extraction were examined in this study, namely; the miRNeasy® mini kit (Cat no: 217004, Qiagen, Düsseldorf, Germany), the miRVana ${ }^{\mathrm{TM}}$ miRNA isolation kit (Cat no: AM1560, Ambion ${ }^{\circledR}$, Austin, TX, USA), and an in-house modified version of the miRVana ${ }^{\mathrm{TM}}$ isolation kit. The manufacturer's protocols for the kits were followed with the exception of the modified miRVana ${ }^{\mathrm{TM}}$ method. With this method, the kit lysis

solution and homogenate solution were replaced with the use of TRIzol ${ }^{\mathrm{TM}}$ and chloroform in order to achieve greater phase separation. Following this step, the manufacturer's instructions were followed. All extracts were eluted in 50 $\mu \mathrm{L}$ of nuclease free water and stored at $-36^{\circ} \mathrm{C}$ until required.

\subsection{RNA Quantitation}

After miRNA had been extracted from the body fluid samples, quantification of the extracts were performed using an EON Microplate Spectrophotometer (BioTek $\left.{ }^{\circledR}\right)$. For miRNA expression analysis it is vital to verify that pure and undamaged RNA has been extracted from the body fluid samples. The spectrophotometer provides an accurate measurement of concentrations $\left(\mathrm{A}_{260}\right)$ and protein contamination (ratio $\mathrm{A}_{260 / 280}$ ). Within the eluate, pure RNA will usually have $\mathrm{A}_{260 / 280}$ ratios between 1.8 and 2.2. The volume of miRNA solution required to yield $1 \mu \mathrm{g}$ of RNA was then calculated.

\section{4 cDNA Synthesis}

All experimentation was carried out in a vented hood which was cleaned with $70 \%$ Industrial Denatured Alcohol and had undergone UV cleaning for 15 minutes before use. Reverse Transcription (RT) was performed to reverse transcribe miRNA into complementary DNA (cDNA) by using miRNA, the TaqMan ${ }^{\circledR}$ MicroRNA Reverse Transcription Kit (Applied Biosystems) as per the manufacturer's protocol, and target-specific stem-loop primers (applied Biosystems). $10 \mathrm{ng}$ of RNA was added to the reaction mix containing RT primers, MultiScribe ${ }^{\mathrm{TM}}$ reverse transcriptase, dNTPs, RNase inhibitor and reverse transcription buffer, with a final reaction volume of $15 \mu \mathrm{L}$. miR-16 was used as an endogenous control for all five body fluids types. miR-451 and miR-412 were used as targets for venous blood and menstrual blood, while miR-205, miR-124a, and miR-891a were used as targets for semen, vaginal secretions, and saliva. The RT reaction was performed using a GeneAMP ${ }^{\circledR}$ PCR System 9700 Thermal Cycler (Applied Biosystems) with the following cycling conditions: $16^{\circ} \mathrm{C}$ for $30 \mathrm{~min}, 42{ }^{\circ} \mathrm{C}$ for $30 \mathrm{~min}, 85{ }^{\circ} \mathrm{C}$ for 5 min, and then remains constant at $4^{\circ} \mathrm{C}$. An RT blank control was prepared within each group of reactions, this blank consisted of the RT master mix with molecular biology grade water, not containing any RNA within the sample. After all RT reactions had completed, all samples were centrifuged before being transferred to a new sterile centrifuge tube and stored at $-20^{\circ} \mathrm{C}$.

\section{$2.5 R T-q P C R$}

RT-qPCR reactions were performed using target-specific TaqMan ${ }^{\circledR}$ Assays (Applied Biosystems, Foster City, CA, USA) and the TaqMan® Universal PCR Master Mix II, No AmpErase® UNG (Cat no: 4440040, Applied Biosystems, Foster City, CA, USA) as per the manufacturer's protocol. Each $20 \mu \mathrm{L}$ reaction volume contained 0.7 
$\mu \mathrm{L}$ of the appropriate $\mathrm{RT}$ reaction product, $1 \mathrm{X}$ TaqMan ${ }^{\circledR}$ Universal PCR Master Mix and $1 \mathrm{X}$ specific TaqMan ${ }^{\circledR}$ Assay. PCR reactions were performed using a 7500 Real-Time PCR System (Applied Biosystems) with the following cycling conditions: $50^{\circ} \mathrm{C}$ for $2 \mathrm{~min}, 95^{\circ} \mathrm{C}$ for $10 \mathrm{~min}$, and 40 cycles of $95^{\circ} \mathrm{C}$ for $15 \mathrm{~s}$ and $60^{\circ} \mathrm{C}$ for $1 \mathrm{~min}$. A no target control (NTC) and reverse transcription blank (RT) was included with each batch of reactions. RT-qPCR reactions were performed in triplicate, and an Inter Assay Control was included on every plate. Data collection was performed during the $60^{\circ} \mathrm{C}$ step by the SDS software version 1.2 (Life Technologies).

\subsection{Data Analysis}

The miRNA targets of interest were expressed relative to miR-16. An average $\mathrm{C}_{\mathrm{T}}$ value was obtained from the triplicate of each sample. The average $\mathrm{C}_{\mathrm{T}}$ for the endogenous control was subtracted from the target miRNA of

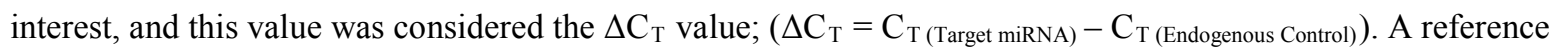
sample was then chosen, which is the sample with the lowest expression and highest $\Delta \mathrm{C}_{\mathrm{T}}$ value. The reference sample was then subtracted from all the $\Delta \mathrm{C}_{\mathrm{T}}$ values, and this value was termed $\Delta \Delta \mathrm{C}_{\mathrm{T}} ;\left(\Delta \Delta \mathrm{C}_{\mathrm{T}}=\Delta \mathrm{C}_{\mathrm{T} \text { (sample 1) }}-\Delta \mathrm{C}_{\mathrm{T}}\right.$ (Reference Sample)). The $\Delta \Delta \mathrm{C}_{\mathrm{T}}$ values were converted to a linear form using the formula; $\mathrm{RQ}=2^{-\Delta \Delta \mathrm{CT}}$. The Relative Quantification (RQ) is the fold change compared to the calibrator. All results were log transformed for analysis in order to stabilize the within-group variances and to create a normal distribution for parametric analysis. Statistical analysis was carried out using the statistical software package Minitab 17.0 (Minitab Ltd.). Two sample T-tests and one-way ANOVA were used to determine association and comparison between different groups and to determine possible significance. Results with a p-value less than 0.05 were considered to be statistically significant.

\section{RESULTS}

\subsection{Optimal Extraction Method}

The first aim of this research was to investigate three methods of miRNA isolation, using two commercial kits, for use with forensically relevant body fluids. The quantitative results for each of the five body fluid extracts using each of the three extraction methods revealed the miRNeasy ${ }^{\circledR}$ mini kit to produce consistently high yields of extracted miRNA (Table 1).

\begin{tabular}{|r|r|r|r|}
\hline & miRNeasy & miRVana & Modified miRVana $^{\mathrm{TM}}$ \\
\hline Venous Blood & $29.3 \pm 6.4$ & $4.5 \pm 1.5$ & $14.8 \pm 18.2$ \\
\hline Menstrual Blood & $232.2 \pm 188.6$ & $56.4 \pm 53.4$ & $53.6 \pm 61.5$ \\
\hline Semen & $83.8 \pm 101.5$ & $13.6 \pm 10.3$ & $16.8 \pm 9.8$ \\
\hline Saliva & $65.7 \pm 50.3$ & $5.9 \pm 4.7$ & $67.5 \pm 47.3$ \\
\hline Vaginal Material & $331.6 \pm 226$ & $111.9 \pm 68.5$ & $110.3 \pm 58.8$ \\
\hline
\end{tabular}

Table 1. Extracted mean yields $(\mathrm{ng} / \mu \mathrm{L})$ and standard deviations of each body fluid with each extraction method.

The yields obtained from venous blood using the miRVana ${ }^{\mathrm{TM}}$ miRNA isolation kit were consistent throughout all 10 samples (mean $4.5 \mathrm{ng} / \mu \mathrm{L}, \pm 1.5$ ), however were much lower than those collected using the miRNeasy ${ }^{\circledR}$ mini kit 
(mean $29.3 \mathrm{ng} / \mu \mathrm{L}, \pm 6.4$ ). The Modified miRVana ${ }^{\mathrm{TM}}$ method produced higher yields than the straightforward miRVana ${ }^{\mathrm{TM}}$ kit (mean $14.8 \mathrm{ng} / \mu \mathrm{L}, \pm 18.2$ ) however, two of the ten samples, produced much higher yields and therefore skews the standard deviation. The quantitative results of the menstrual blood, semen, saliva, and vaginal material extracts using each of the three extraction methods revealed the miRNeasy ${ }^{\circledR}$ mini kit to again produce consistently higher yields of extracted miRNA when compared to the other two methods. It should be noted the yields obtained using the miRNeasy ${ }^{\circledR}$ mini kit varied widely within the samples and across the body fluids, however, they were consistently higher than that of the other two extraction methods. The miRNeasy® mini kit was demonstrated to have the highest average yield within all the tested body fluids, with the exception of saliva which had a slightly higher average yield with the modified miRVana ${ }^{\mathrm{TM}}$ method.

\subsection{RT-qPCR Validation of miRNA Targets}

RT-qPCR was performed targeting a specific miRNA in each body fluid. The expression of miR-451 was examined in venous blood samples and menstrual blood samples. A two sample T-test found miR-451 expression to be significantly dysregulated in the venous blood samples $\left(1.1442 \pm 0.0644, \log _{10} R Q\right)$ when compared to the menstrual blood samples $\left(2.06 \pm 1.22, \log _{10} \mathrm{RQ}, \mathrm{p}<0.001\right.$, Figure 1$)$.

\section{miR-451 Expression}

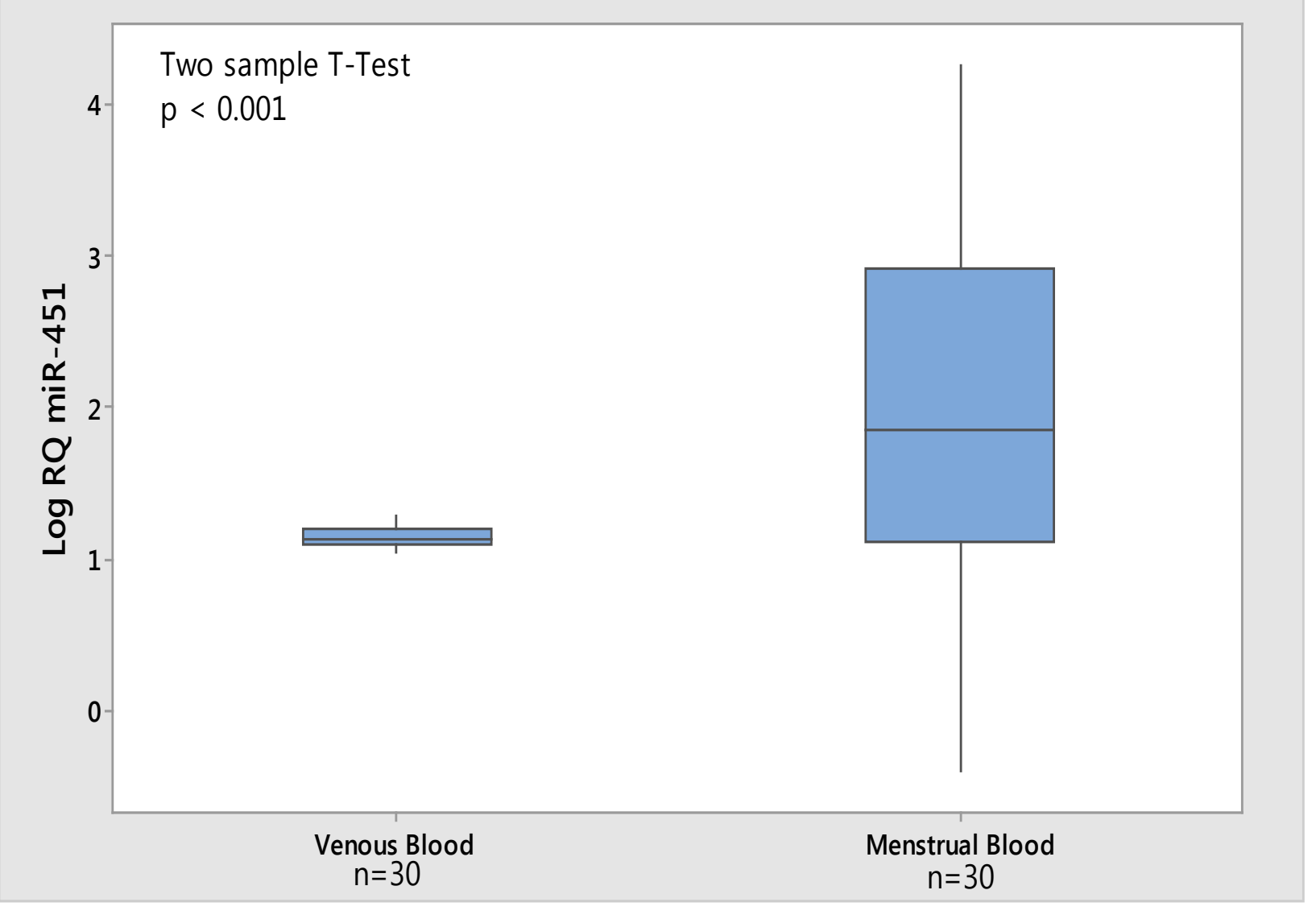


Figure 1. miR-451 expression between venous blood and menstrual blood.

It can also be observed that miR-451 was very stably expressed as it has a condensed narrow range. These results highlight the potential of miR-451 as a biomarker for venous blood.

The expression of miR-412 was examined in menstrual blood samples and venous blood samples. A two sample Ttest found miR-412 expression to be significantly down regulated in menstrual blood samples $\left(0.473 \pm 0.312, \log _{10}\right.$ $\mathrm{RQ})$ when compared to the venous blood samples $\left(1.088 \pm 0.600, \log _{10} \mathrm{RQ}, \mathrm{p}<0.001\right.$, Figure 2$)$.

\section{miR-412 Expression}

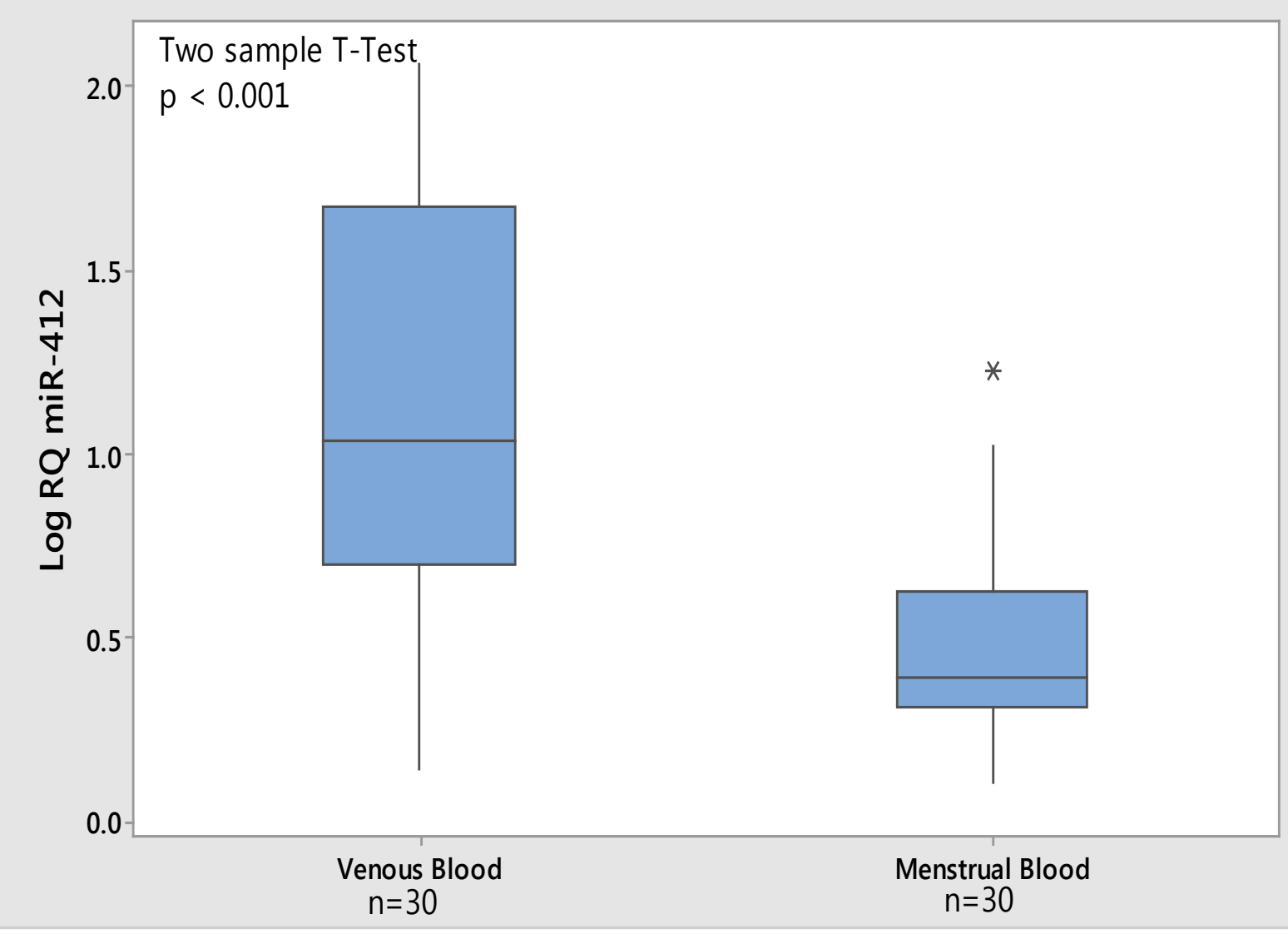

Figure 2. miR-412 expression between menstrual blood and venous blood.

It can also be seen that miR-412 was stably expressed as it has a narrow range in the menstrual blood samples.

These results highlight the potential of miR-412 as a biomarker for menstrual blood.

The expression of miR-891a was examined in semen samples, vaginal material samples, and saliva samples. miR$891 \mathrm{a}$ expression was found to be significantly upregulated in the semen samples $\left(2.9341 \pm 1.0241, \log _{10} R Q\right)$ when 
compared to the vaginal material $\left(0.8948 \pm 0.6911, \log _{10} R Q\right)$ and saliva samples $\left(0.6686 \pm 0.4700, \log _{10} R Q\right.$, ANOVA $\mathrm{p}<0.001$, Figure 3).

\section{miR-891a Expression}

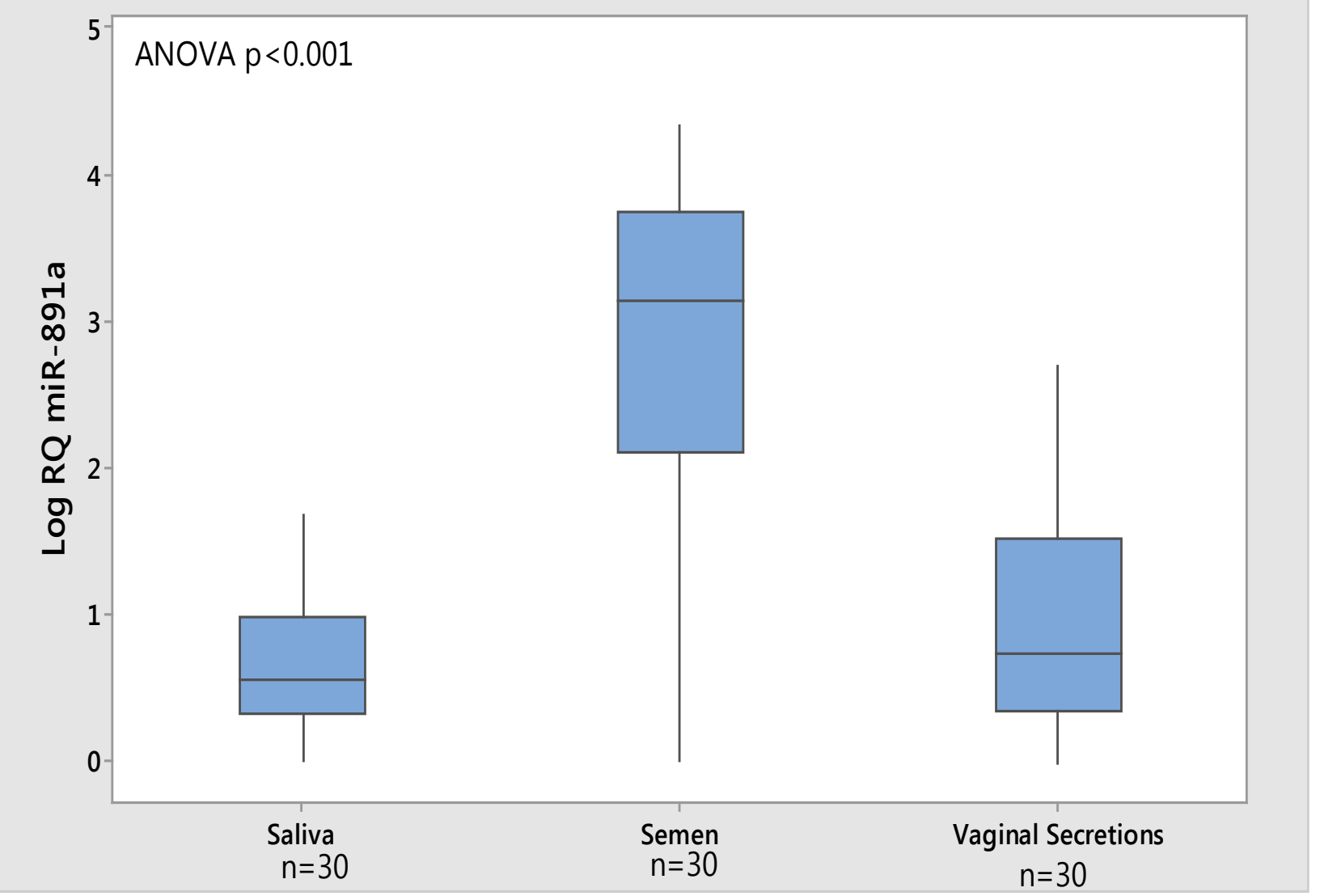

Figure 3. miR-891a expression across semen, vaginal material, and saliva samples.

An analysis of variance (ANOVA) was performed, providing a p value of less than 0.001 across the three body fluids. This significance remained true when observing the body fluids individually, with semen compared to saliva and semen compared to vaginal secretions. These results highlight the potential of miR-891a as a biomarker for semen.

The expression of miR-205 was examined in saliva samples, semen samples, and vaginal secretion samples. miR205 expression was found to be significantly dysregulated across all three body fluid samples; saliva $\left(0.9761 \pm 0.5637, \log _{10} R Q\right)$, semen $\left(2.3117 \pm 1.1398, \log _{10} R Q\right)$, and vaginal material $\left(1.0231 \pm 0.8107, \log _{10} R Q\right.$, ANOVA $\mathrm{p}<0.001$, Figure 4). 


\section{miR-205 Expression}

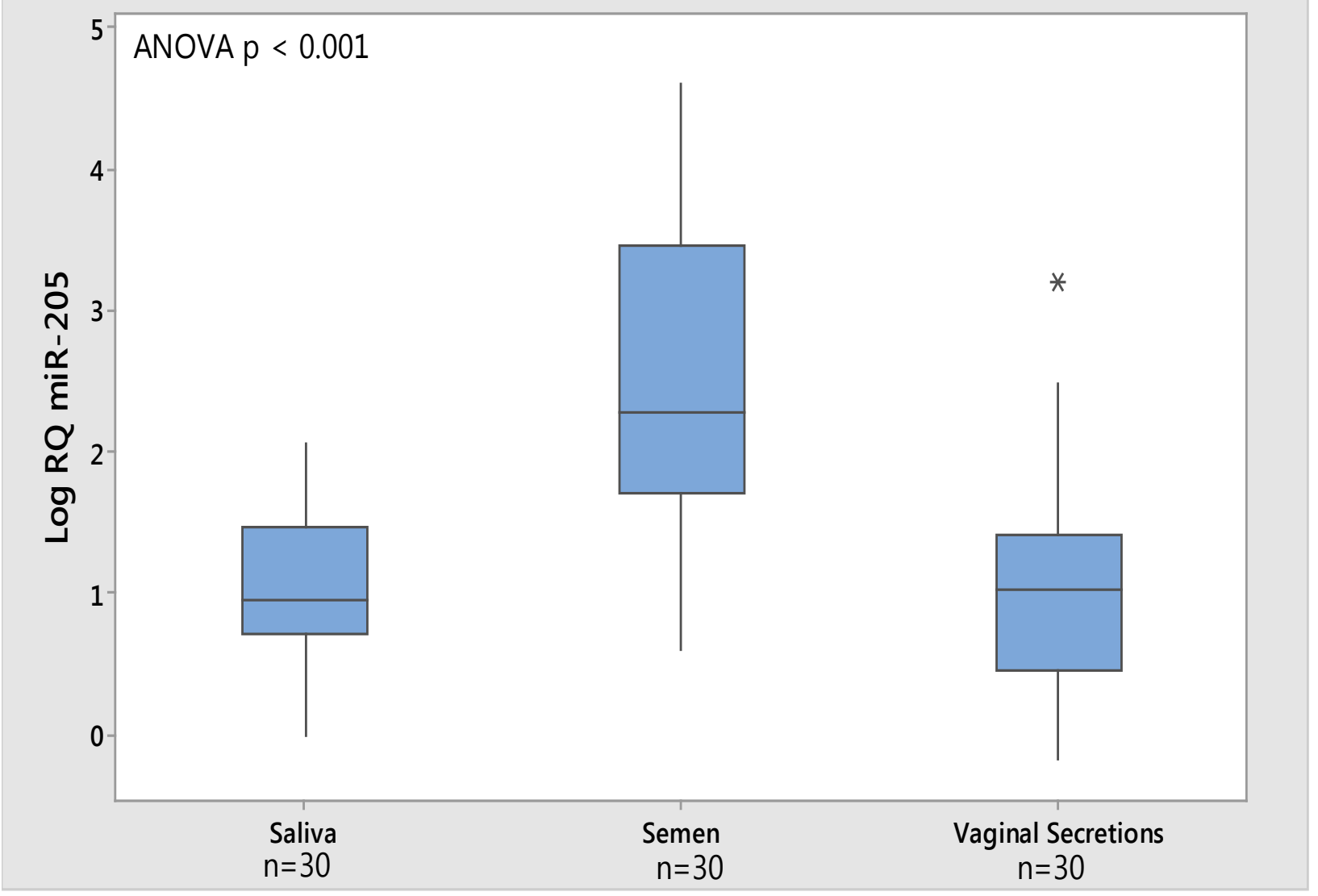

Figure 4. miR-205 expression across saliva, semen, and vaginal material samples.

An ANOVA test was performed, providing a p value of less than 0.001 . When saliva samples were compared with semen samples, significance was observed with a $\mathrm{p}$ value of less than 0.001 . However when comparing saliva samples to vaginal secretion samples, there was no significance

observed. These results highlight the potential of miR-205 to differentiate between saliva and semen, but not vaginal secretions.

The expression of miR-124a was examined in vaginal secretion samples, semen samples, and saliva samples. miR124a expression was found to be significantly dysregulated across all three body fluid samples; saliva (1.423 \pm 0.753 , $\log _{10}$ RQ), semen $\left(0.172 \pm 2.664, \log _{10}\right.$ RQ), and vaginal material $\left(0.454 \pm 0.572, \log _{10}\right.$ RQ, ANOVA p $<0.05$, Figure 5). 


\section{miR-124a Expression}

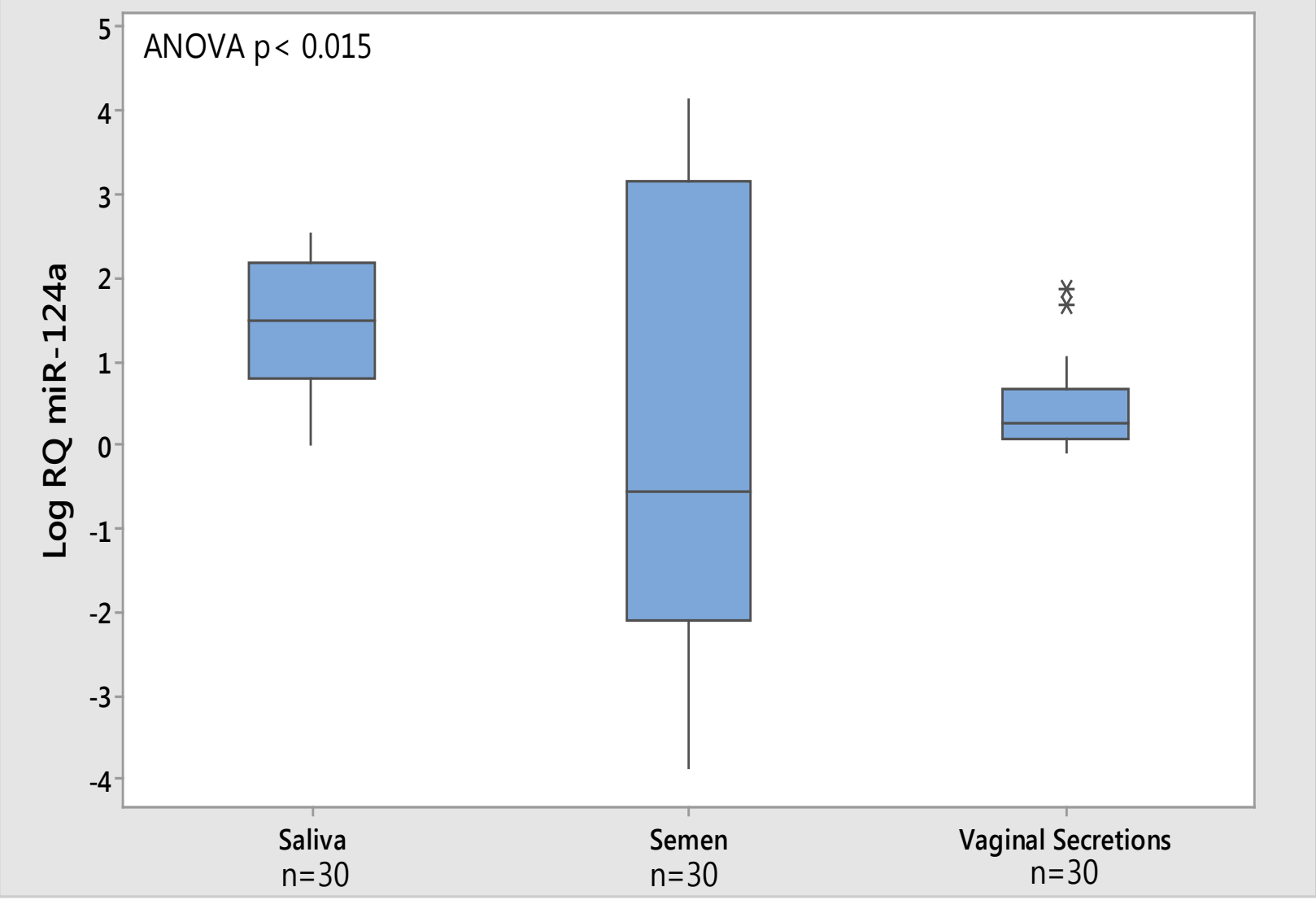

Figure 5. miR-124a expression across vaginal material, semen, and saliva samples.

An ANOVA test was performed across all three body fluids, providing a $p$ value of less than 0.05 . When vaginal material samples were compared with saliva samples, significance was observed with a p value of less than 0.001 . When comparing vaginal material samples to semen samples, there was no significance observed. These results highlight the potential of miR-124a to differentiate between vaginal secretions and saliva, but not semen samples. 


\section{DISCUSSION}

The aim of this research was to first identify the optimal method of miRNA extraction from forensically relevant body fluids using the methods investigated, and second to validate previously reported miRNAs in those body fluids. While there are several commercial miRNA extraction kits available (RNeasy ${ }^{\circledR}$ Micro kit (Qiagen), miRNeasy ${ }^{\circledR}$ Mini kit (Qiagen), mirVana ${ }^{\mathrm{TM}}$ miRNA isolation kit (Applied Biosystems) and RNAqueous ${ }^{\circledR}$-Micro kit (Ambion)), all of these kits are designed to be used with clinical samples, such as tissues and cultured/primary cells. Therefore, it was crucial that some kits were compared for use with forensically relevant body fluids. In this study, miRNA was isolated from venous blood, menstrual blood, semen, saliva, and vaginal material, using three different extraction methods, namely; miRNeasy ${ }^{\circledR}$ mini kit (Qiagen), the miRVana ${ }^{\mathrm{TM}}$ isolation kit (Ambion), and an in-house modified version of the miRVana ${ }^{\mathrm{TM}}$ isolation kit.

The miRNeasy ${ }^{\circledR}$ mini kit (Qiagen) combines phenol/guanidine-based lysis of samples and a silica membrane column based purification. The mirVana ${ }^{\mathrm{TM}}$ miRNA Isolation Kit (Ambion $\left.{ }^{\circledR}\right)$ employs organic extraction followed by purification on two sequential glass fiber filters (GFF) under specialized binding and wash conditions. Unlike other methods, the mirVana ${ }^{\mathrm{TM}}$ kit utilizes two sequential GFFs, as it has been suggested that the small RNAs are essentially lost in the first filtration through the column and therefore a second filtration is required to capture the miRNAs. For the modified miRVana ${ }^{\mathrm{TM}}$ method, the kit lysis solution and homogenate solution were replaced with TRIzol $^{\mathrm{TM}}$ and choroform in order to achieve greater phase separation. The miRNeasy® mini kit was shown to provide consistently higher yields in the samples of each body fluid, with slight variation seen within a body fluid. Venous blood yielded the lowest quantities of extracted miRNA suggesting the need to develop a specialized method for extraction from whole blood. Menstrual blood and vaginal material revealed the highest yields, however it should be noted that the method of quantitation is not human specific and therefore it could be suggested that the high yield could be as a result of bacterial contamination. Human specific quantitation would be the authors preferred method for quantitation however was not available to the authors. Spectrophotometric methods of quantitation using instruments such as the BioTech spectrophotometer or the Nanodrop spectrophotometer have been widely used to measure nucleic acids for a less specific yet reliable method. The average quantities obtained for each body fluid were examined, and although there was slight variation depending on the fluid type, it was concluded that the miRNeasy ${ }^{\circledR}$ mini kit was the optimal method of three tested for the extraction of miRNA, because of its higher quantitative yields with each body fluid. The ability to obtain a sufficient quantity and quality of miRNA from a sample is a crucial step in the identification of forensically relevant body fluids using miRNA.

Three accepted methods for analysis of miRNA expression include; Northern Blotting, Microarrays, and Real-Time Quantitative PCR. In 2010 Zubakov et al. published a study which incorporated all three of these technique [27]. As miRNA research has progressed, the Real-Time Quantitative PCR technique has become the gold standard, due to its ease of use and the robustness of the technique, and therefore was the method of choice for this study. A normalization strategy was implemented using a housekeeping gene to calculate the Relative Quantification (RQ) of the sample [37-38]. MiR-16 was used as the housekeeping gene in this study as it had been previously reported to exhibit little variability across a number of body fluids, tissues, and cell lines [39-42] . Since the time of 
experimentation however, other housekeeping genes have been suggested for forensically relevant body fluids which should be considered in the future [43]. RT-qPCR validation was performed using five miRNAs, namely; miR-451, miR-891a, miR-205, miR-124a, and miR-412, and their differential expression patterns were analyzed in various body fluids where the ability to differentiate between them is of particular importance e.g. venous blood versus menstrual blood. The miRNAs investigated in this study were previously suggested in the literature to show potential as biomarkers for particular body fluids. MiR-451, which was suggested for venous blood [25-26, 28, 4445], showed significant downregulation in the venous blood samples when compared to menstrual blood, highlighting its potential as a biomarker for venous blood. It was also observed that miR-451 was very stably expressed across the venous blood samples analyzed further highlighting its potential as a biomarker for venous blood. MiR-412, which was suggested for menstrual blood [26, 46], showed significant downregulation in the menstrual blood samples when compared to venous blood, highlighting its potential as a biomarker for menstrual blood. It should also be noted that miR-412 expression was more stably expressed across the menstrual blood samples when compared to the venous blood samples. MiR-891a, which was suggested for semen [19, 27, 29], showed significant upregulation in the semen samples when compared across the saliva and vaginal material samples. It should also be noted that this significant upregulation was maintained when the semen samples were compared individually to the saliva samples, and then compared to the vaginal material samples. This further highlights miR-891a's potential as a biomarker for semen. MiR-205, which was suggested for saliva [25-26], showed significant dysregulation when compared across the three sample types; saliva, semen, and vaginal material. However, when compared individually, miR-205 was significantly downregulated when compared to the semen samples, but this significance was lost when compared to the vaginal material samples. This highlights the potential of miR-205 to differentiate between saliva and semen, but not saliva and vaginal material. MiR-124a, which was suggested for vaginal secretions [26, 29], showed significant dysregulation when compared across the three sample types; saliva, semen, and vaginal material. However, when compared individually, miR-124a was significantly downregulated in vaginal material when compared to saliva, but this significance was lost when compared to the semen samples. This highlights the potential of miR-124a to differentiate between vaginal material and saliva, but not vaginal material and semen. This study has revealed three miRNAs to show potential as novel biomarkers for particular body fluids, while two miRNAs have been shown to be able to differentiate between two body fluids.

\section{CONCLUSION}

This study has identified the optimal method, from the three methods investigated, for extraction of miRNAs from body fluids, and further validates a selection of miRNAs previously suggested as potential biomarkers. This research highlights the potential of miRNAs as novel molecular markers for the confirmatory identification of forensically relevant body fluids. 


\section{CONFLICT OF INTEREST}

The authors have no conflicts of interest.

\section{REFERENCES}

1. Gill P, Jeffreys AJ, Werrett DJ. Forensic application of DNA 'fingerprints'. Nature. 1985;318(6046):577-9.

2. Virkler K, Lednev IK. Analysis of body fluids for forensic purposes: from laboratory testing to nondestructive rapid confirmatory identification at a crime scene. Forensic Sci Int. 2009;188(1-3):1-17.

3. Bauer M, Patzelt D. Evaluation of mRNA markers for the identification of menstrual blood. J Forensic Sci. 2002;47(6):1278-82.

4. Bauer M, Patzelt D. Identification of menstrual blood by real time RT-PCR: technical improvements and the practical value of negative test results. Forensic Sci Int. 2008;174(1):55-9.

5. Juusola J, Ballantyne J. Messenger RNA profiling: a prototype method to supplant conventional methods for body fluid identification. Forensic Sci Int. 2003;135(2):85-96.

6. Juusola J, Ballantyne J. Multiplex mRNA profiling for the identification of body fluids. Forensic Sci Int. 2005;152(1):1-12.

7. Juusola J, Ballantyne J. mRNA profiling for body fluid identification by multiplex quantitative RT-PCR. J Forensic Sci. 2007;52(6):1252-62.

8. van den Berge M, Carracedo A, Gomes I, Graham EA, Haas C, Hjort B, et al. A collaborative European exercise on mRNA-based body fluid/skin typing and interpretation of DNA and RNA results. Forensic Sci Int Genet. 2014;10:40-8.

9. Sijen T. Molecular approaches for forensic cell type identification: On mRNA, miRNA, DNA methylation and microbial markers. Forensic Sci Int Genet. 2015;18:21-32.

10. Vennemann M, Koppelkamm A. mRNA profiling in forensic genetics I: Possibilities and limitations. Forensic Sci Int. 2010;203(1-3):71-5.

11. Setzer M, Juusola J, Ballantyne J. Recovery and stability of RNA in vaginal swabs and blood, semen, and saliva stains. J Forensic Sci. 2008;53(2):296-305.

12. Lee J, Hever A, Willhite D, Zlotnik A, Hevezi P. Effects of RNA degradation on gene expression analysis of human postmortem tissues. FASEB J. 2005;19(10):1356-8.

13. Bauer M, Polzin S, Patzelt D. Quantification of RNA degradation by semi-quantitative duplex and competitive RT-PCR: a possible indicator of the age of bloodstains? Forensic Sci Int. 2003;138(1-3):94-103.

14. Jung M, Schaefer A, Steiner I, Kempkensteffen C, Stephan C, Erbersdobler A, et al. Robust microRNA stability in degraded RNA preparations from human tissue and cell samples. Clin Chem. 2010;56(6):998-1006.

15. Lee RC, Feinbaum RL, Ambros V. The C. elegans heterochronic gene lin-4 encodes small RNAs with antisense complementarity to lin-14. Cell. 1993;75(5):843-54. 
16. Lee RC, Ambros V. An extensive class of small RNAs in Caenorhabditis elegans. Science. 2001;294(5543):862-4.

17. Lau NC, Lim LP, Weinstein EG, Bartel DP. An abundant class of tiny RNAs with probable regulatory roles in Caenorhabditis elegans. Science. 2001;294(5543):858-62.

18. Lagos-Quintana M, Rauhut R, Meyer J, Borkhardt A, Tuschl T. New microRNAs from mouse and human. RNA. 2003;9(2):175-9.

19. Landgraf P, Rusu M, Sheridan R, Sewer A, Iovino N, Aravin A, et al. A mammalian microRNA expression atlas based on small RNA library sequencing. Cell. 2007;129(7):1401-14.

20. Sood P, Krek A, Zavolan M, Macino G, Rajewsky N. Cell-type-specific signatures of microRNAs on target mRNA expression. Proc Natl Acad Sci U S A. 2006;103(8):2746-51.

21. Liang Y, Ridzon D, Wong L, Chen C. Characterization of microRNA expression profiles in normal human tissues. BMC Genomics. 2007;8:166.

22. Kulstein G, Marienfeld R, Miltner E, Wiegand P. Automation of DNA and miRNA co-extraction for miRNA-based identification of human body fluids and tissues. Electrophoresis. 2016;37(21):2742-50.

23. van der Meer D, Uchimoto ML, Williams G. Simultaneous analysis of micro-RNA and DNA for determining the body fluid origin of DNA profiles. J Forensic Sci. 2013;58(4):967-71.

24. Li Y, Zhang J, Wei W, Wang Z, Prinz M, Hou Y. A strategy for co-analysis of microRNAs and DNA. Forensic Sci Int Genet. 2014;12:24-9.

25. Omelia EJ, Uchimoto ML, Williams G. Quantitative PCR analysis of blood- and saliva-specific microRNA markers following solid-phase DNA extraction. Anal Biochem. 2013;435(2):120-2.

26. Hanson EK, Lubenow H, Ballantyne J. Identification of forensically relevant body fluids using a panel of differentially expressed microRNAs. Anal Biochem. 2009;387(2):303-14.

27. Zubakov D, Boersma AW, Choi Y, van Kuijk PF, Wiemer EA, Kayser M. MicroRNA markers for forensic body fluid identification obtained from microarray screening and quantitative RT-PCR confirmation. Int J Legal Med. 2010;124(3):217-26.

28. Courts C, Madea B. Specific micro-RNA signatures for the detection of saliva and blood in forensic bodyfluid identification. J Forensic Sci. 2011;56(6):1464-70.

29. Wang Z, Zhang J, Luo H, Ye Y, Yan J, Hou Y. Screening and confirmation of microRNA markers for forensic body fluid identification. Forensic Sci Int Genet. 2013;7(1):116-23.

30. Hanson EK, Mirza M, Rekab K, Ballantyne J. The identification of menstrual blood in forensic samples by logistic regression modeling of miRNA expression. Electrophoresis. 2014;35(21-22):3087-95.

31. Park JL, Park SM, Kwon OH, Lee HC, Kim JY, Seok HH, et al. Microarray screening and qRT-PCR evaluation of microRNA markers for forensic body fluid identification. Electrophoresis. 2014;35(21-22):3062-8.

32. Sauer E, Reinke AK, Courts C. Differentiation of five body fluids from forensic samples by expression analysis of four microRNAs using quantitative PCR. Forensic Sci Int Genet. 2016;22:89-99.

33. Hanson EK, Ballantyne J. Circulating microRNA for the identification of forensically relevant body fluids. Methods Mol Biol. 2013;1024:221-34. 
34. Weber JA, Baxter DH, Zhang S, Huang DY, Huang KH, Lee MJ, et al. The microRNA spectrum in 12 body fluids. Clin Chem. 2010;56(11):1733-41.

35. Wang Z, Luo H, Pan X, Liao M, Hou Y. A model for data analysis of microRNA expression in forensic body fluid identification. Forensic Sci Int Genet. 2012;6(3):419-23.

36. Wang Z, Zhang J, Wei W, Zhou D, Luo H, Chen X, et al. Identification of Saliva Using MicroRNA Biomarkers for Forensic Purpose. J Forensic Sci. 2015;60(3):702-6.

37. Livak KJ, Schmittgen TD. Analysis of relative gene expression data using real-time quantitative PCR and the 2(-Delta Delta C(T)) Method. Methods. 2001;25(4):402-8.

38. Vandesompele J, De Preter K, Pattyn F, Poppe B, Van Roy N, De Paepe A, et al. Accurate normalization of real-time quantitative RT-PCR data by geometric averaging of multiple internal control genes. Genome Biol. 2002;3(7):RESEARCH0034.

39. Bhattacharya R, Nicoloso M, Arvizo R, Wang E, Cortez A, Rossi S, et al. MiR-15a and MiR-16 control Bmi-1 expression in ovarian cancer. Cancer Res. 2009;69(23):9090-5.

40. McDermott AM, Kerin MJ, Miller N. Identification and validation of miRNAs as endogenous controls for RQ-PCR in blood specimens for breast cancer studies. PLoS One. 2013;8(12):e83718.

41. Sourvinou IS, Markou A, Lianidou ES. Quantification of circulating miRNAs in plasma: effect of preanalytical and analytical parameters on their isolation and stability. J Mol Diagn. 2013;15(6):827-34.

42. Das MK, Andreassen R, Haugen TB, Furu K. Identification of Endogenous Controls for Use in miRNA Quantification in Human Cancer Cell Lines. Cancer Genomics Proteomics. 2016;13(1):63-8.

43. Sauer E, Babion I, Madea B, Courts C. An evidence based strategy for normalization of quantitative PCR data from miRNA expression analysis in forensic organ tissue identification. Forensic Sci Int Genet. 2014;13:21723.

44. Dunnett H, van der Meer D, Williams GA. Evaluation of stem-loop reverse transcription and poly-A tail extension in microRNA analysis of body fluids. MicroRNA. 2014;3(3):150-4.

45. Courts C, Madea B. Micro-RNA - A potential for forensic science? Forensic Sci Int. 2010;203(1-3):106-11. 46. Bexon K, Williams, G. Characterising the fluctuation of microRNA expression throughout a full menstrual cycle. Forensic Science International: Genetics Supplement Series. 2015;5:264-6. 